\title{
VORTEX COOLED AIR TURNING OF INDUCTION-HARDENED RACEWAY ON THE WIND TURBINE-BEARING RING
}

\author{
Mladen BOŠNJAKOVIĆ, Olivera MAGLIĆ, Dragomir MOŠKUN, Zoran CRNAC
}

\begin{abstract}
In the turning process of hard materials with CBN cutting inserts, metalworking fluid is not advisable as it results in poorer quality of finished surface and shortening of the tool life. Dry machining, otherwise, develops excessive heat, residual stresses in the workpiece material due to thermal stress, and therefore causes possible problems of achieving tolerances on larger workpieces. During the dry turning of induction hardened raceway on the wind turbine-bearing ring of $1500 \mathrm{~mm}$ in diameter, problems with achieving tolerances occurred. The vortex-cooled air implementation during turning resulted in achieving designing tolerances of the workpiece, with better surface roughness and with less tool wear. The result was $50 \%$ lower cost of cutting inserts and small operating costs associated with air consumption. The vortex-cooled air implementation makes it possible to extend the tool life of CBN cutting inserts and thus higher cost-effectiveness of machining.
\end{abstract}

Keywords: cost-effectiveness of machining; turning; vortex-cooled air

\section{INTRODUCTION}

The industrial world is slowly moving toward dry machining as the technology of the future. Development of environmental awareness, concern for human health, and law regulations force industrial production to avoid using cutting fluids and turn to develop and improvement of dry machining.

Drivers for the implementation of a dry cutting are in particular companies with series production in the field of automobile manufacturers and their suppliers. But the transformation from wet to dry cutting comes along with major problems, strong heating of the workpiece during dry cutting, higher tool wear, and finally, thermally caused dimension and form deviations [1]. F. Klocke et al. developed a model to predict and compensate the thermoelastic workpiece deformation [2].

Problems arising from the dry cutting process are specific to each process and each combination of toolworkpiece materials. To apply dry cutting, the most significant changes in the design of manufacturing systems are linked to cooling, additional equipment and adaptation of cutting processes to the new restrictions [3]. Requirements for high dimensional accuracy are still a limiting factor for the application of dry machining. The cooling during the process is necessary when there is strong adhesion between the tool and workpiece or when tool wears is too intensive, or when it is not possible to control the thermal deformation of the workpiece.

A necessary precondition for implementation of dry machining is an acceptable substitution of the functions of cooling and lubricating agents. In first investigations, regular compressed air was used, and its performance was inferior to water and oil [4]. Implementation of cold compressed air obtained better results. Nandy and others had shown that the use of a cold compressed air maximizes tool lifetime and machining productivity, giving the opportunity to use higher machining parameters related to dry machining $[5,6]$.
Cutting fluids could be replaced by cold compressed air, to cool and to remove chips from cutting area. Compared to cutting fluids, this technique significantly cut production costs, and it is not harmful to the environment and human health [7]. Applying cold air to the tool interface of these modern tooltip will also extend their tool life reducing the cost of metal-cutting.

With regard to the workpiece type, implementing dry machining instead of conventional wet machining will get savings of total costs for $17 \%$. This will happen due to the elimination of cutting fluids, cleaning of the machine, maintenance and removing cutting fluids [8].

Cho and other investigated influence of cold compressed air at $-4{ }^{\circ} \mathrm{C}$ to $-25{ }^{\circ} \mathrm{C}$ pressure of 4 bar and showed that lowering the air temperature will increase surface quality and decrease residual stress [9].

Cooling with cold compressed air is usually performed by vortex tube.

The vortex tube is known as the Ranque-Hilsch vortex tube. It is a device that enables separation of hot and cold air during the flow of compressed air through an inlet nozzle tangential to the vortex chamber. Vortex tube was invented in 1933 by a French metallurgist and physicist Georges Ranque and improved by German physicist Rudolf Hilsch.

Although the basic work principle of the vortex tube is known, details of the process are still investigated, recently with Computational fluid dynamics (CFD) simulation [10]. Besides that, the influence of the geometry of the vortex tube to fluid stream parameters is also investigated.

The vortex tube is a simple device, which does not have moving parts and simultaneously produces a hot and cold stream of air at two ends from the source of compressed air.

It consists of a long tube that has a tangential nozzle at one end and valve at the other end, as shown in Fig. 1. Compressed air is introduced in the tube by a tangential nozzle that creates a vortex of the inlet air stream (in some cases over million rounds per minute) [11]. 
Air vortex is moving toward an adjustable valve at the hot end that controls the volume of the airflow and the temperature existing at the cold end. By adjusting the valve, you control the "cold fraction", which is the percentage of the total input of compressed air that exits the cold end of the Vortex Tube.

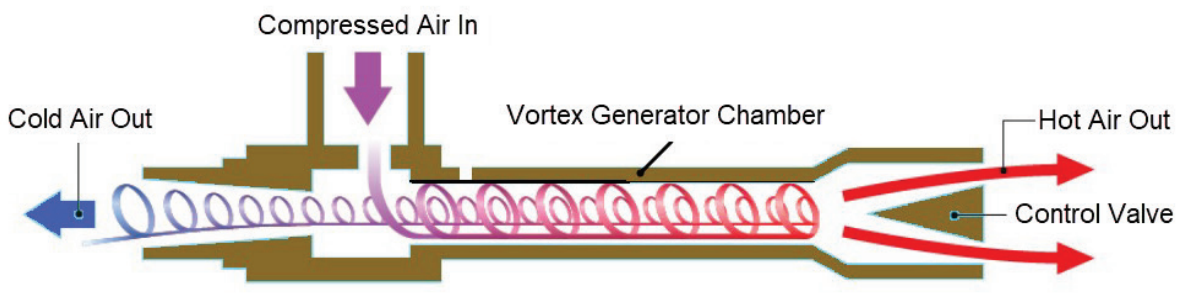

Figure 1 Scheme presenting Ranque-Hilsch tube

The adjustable valve leaks smaller part of the swirling air along the wall of the tube ( $20 \%$ to $40 \%)$, and central part of air vortex is directed in the opposite direction creating inner vortex through outer air vortex. Inner vortex transfers heat to outer vortex near the wall and, with a significant decrease of temperature, air exits on the cold end of the tube. Outer vortex near tube wall exits on the opposite end with a temperature higher than the temperature of inlet air. Vortex tube has many possible industrial applications and could be used as a cooling device at $\mathrm{CNC}$ machines, in refrigerators, heating processes, etc. High applicability of vortex tube is based on its simplicity, compactness and the fact that the system has a small mass and works in quiet mode. These tubes do not have moving parts, so they do not break or wear which makes them simple for maintenance.

Application of cold air will decrease the temperature at the cutting area during machining; it will decrease the temperature of tool, chip and workpiece due to intense heat removal by convection which emphasizes the importance of convection coefficient for tool temperature modelling. Convection coefficient for cutting fluids based on water is in the range from 103 to $104 \mathrm{~W} /\left(\mathrm{m}^{2} \mathrm{~K}\right)$. Convection coefficient for cold air was investigated for the first time by Liu and Chou [12] and in simulation, it has values in range 50-5000 $\mathrm{W} /\left(\mathrm{m}^{2} \mathrm{~K}\right)$, while in the experiment it is about $160 \mathrm{~W} /\left(\mathrm{m}^{2} \mathrm{~K}\right)$ with applied air of temperature up to $-15{ }^{\circ} \mathrm{C}$ and 860 $\mathrm{W} /\left(\mathrm{m}^{2} \mathrm{~K}\right)$ for cooling with air with temperature up to $-25^{\circ} \mathrm{C}$.

\section{MATERIAL AND METHODS 2.1 Problem Definition}

Example of machining without using cutting fluid is turning on a big vertical turning machine with maximal diameter $4270 \mathrm{~mm}$ with an embedded CNC control system. Although the machine is equipped with an emulsion cooling system, the manufacturer of the CBN (cubic boron nitride) inserts recommends turning without coolant. In accordance with this recommendation, induction hardened ring raceways for big axial bearings were performed.

Final machining of hardened raceway bearing was tried with PCBN (polycrystalline cubic boron nitride) insert without emulsion cooling because due to high temperature in cutting area cooling liquid evaporated and the insert would be damaged.
Machining of material $42 \mathrm{CrMo} 4$ was experimentally investigated by Sutter et al [13]. They determined that at cutting speed around $20 \mathrm{~m} / \mathrm{s}$, the temperature measured near the tool-chip interface achieved a maximal value of $870{ }^{\circ} \mathrm{C}$ for $42 \mathrm{CrMo} 4$. The increase of the cutting speed from $10 \mathrm{~m} / \mathrm{s}$ to $65 \mathrm{~m} / \mathrm{s}$ raises continuously the chips' temperature and influence the location of the maximal temperature.

Table 1 Workpiece basic data

\begin{tabular}{|l|l|}
\hline \multicolumn{1}{|c|}{ Description } & \multicolumn{1}{c|}{ Values } \\
\hline Item name & Inner ring \\
\hline Number of workpieces & 27 \\
\hline Material designation & $42 \mathrm{CrMo} 4 \mathrm{~V}$ \\
\hline Material condition & $\begin{array}{l}\text { Rolled ring, hardened and tempered at } 800- \\
900 \mathrm{MPa}\end{array}$ \\
\hline Machining type & $\begin{array}{l}\text { Final machining of induction hardened } \\
\text { raceway with 56 HRC } \pm 2 \mathrm{HRC} \text { for ball } \varnothing 50\end{array}$ \\
\hline
\end{tabular}

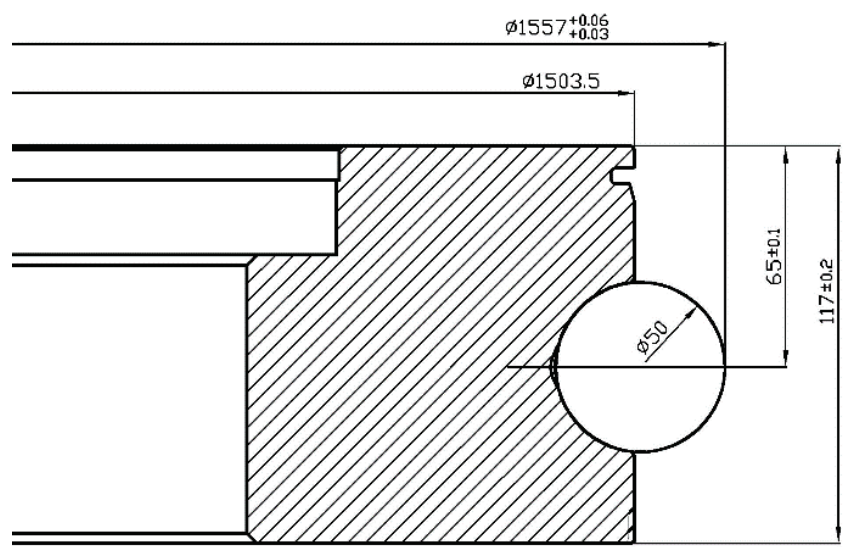

Figure 2 Scheme of inner ring

The dimension of the critical machined surface is measured by stick micrometer on balls $\varnothing 50$ which are set at $180^{\circ}$ on a rolling raceway.

Two persons perform measuring - a worker on the machine and inspector. Results are recorded in the control list due to mounting ring in the axial bearing.

The problem that was noticed 24 hours after the final machining is the change in measure over balls for $0.1 \mathrm{~mm}$ to $0.2 \mathrm{~mm}$ which make impossible to mount two rings in the axial bearing. Rings had to be re-machined.

Requirements to the technology department were to find a solution for how to: 
- decrease stress in the ring which is caused by thermal expansion due to higher ring temperatures during machining,

- perform dimensions in given tolerances,

- decrease tool costs.

All of these requirements should be realized with very limited funding resources.

\subsection{Suggested Solution}

Analysis of literature and taking into account economic and other limiting factors resulted in the proposal of application of cold air for cooling of the tool and workpiece. Installing a cold air nozzle is simple and requires only the installation of compressed air hose on the column of the machine. Accordingly, a SARA vortex tube was purchased.

Table 2 Vortex tube data

\begin{tabular}{|l|l|}
\hline \multicolumn{1}{|c|}{ Description } & \multicolumn{1}{c|}{ Values } \\
\hline Supplier & SARA \\
\hline Air pressure at the inlet & 3 to 5 bars \\
\hline Cold air outlet & lowest $-48^{\circ} \mathrm{C}$ \\
\hline Hot air outlet & do $100{ }^{\circ} \mathrm{C}$ \\
\hline Air consumption at $7-8$ bar & $2701 / \mathrm{min}$ \\
\hline Price of the device & $€ 409+$ VAT \\
\hline
\end{tabular}

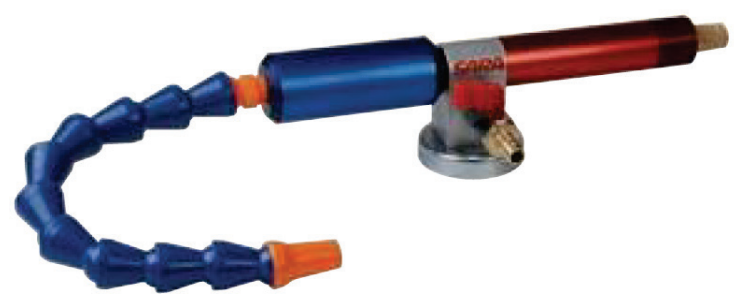

Figure 3 Vortex tube

Table 3 Basic machine data

\begin{tabular}{|l|l|}
\hline \multicolumn{1}{|c|}{ Description } & \multicolumn{1}{c|}{ Values } \\
\hline Machine & Vertical turning machine (See Fig. 3) \\
\hline Year of production & 1984. \\
\hline Max. workpiece diameter & $2500 \mathrm{~mm}$ \\
\hline Max workpiece height & $2000 \mathrm{~mm}$ \\
\hline Total turning height & $900 \mathrm{~mm}$ \\
\hline Cooling system & Exist \\
\hline
\end{tabular}

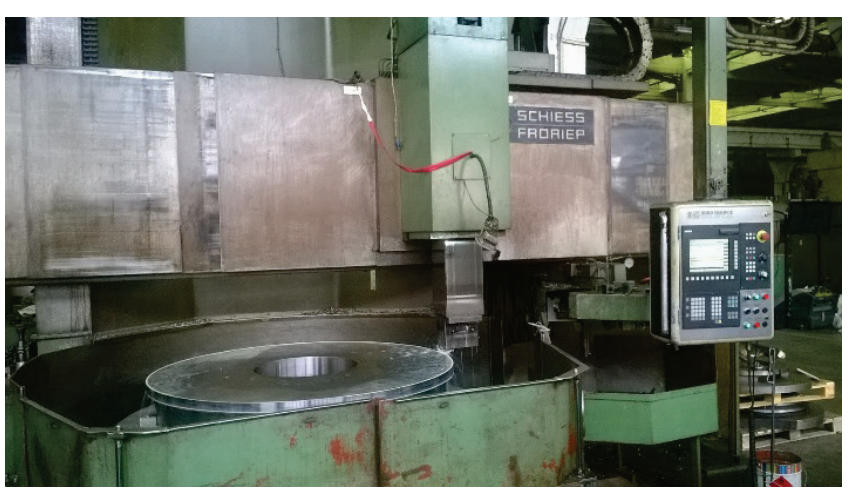

Figure 4 Turning machine
Optimal machining parameters according to the recommendations from literature presents a combination of low feed rate and low depth of cut with higher cutting speed, which is beneficial for reducing cutting temperatures, machining force and surface roughness (Tab. 4).

Table 4 Basic data for insert and final cutting parameters

\begin{tabular}{|l|l|}
\hline \multicolumn{1}{|c|}{ Description } & RCGX Full Face PCBN grade Insert size 0900700T- \\
\hline Insert type & \\
\hline Tool holder & $\begin{array}{l}\text { CRDCN 3225P 09-A } \\
\text { Spindle speed }\end{array}$ \\
\hline Feed rate & $\begin{array}{l}\text { Raceway machining length } l=83 \mathrm{~mm}, \text { number of } \\
\text { passes } i=7\end{array}$ \\
\hline Depth of cut & $\begin{array}{l}\text { Insert machining time for } 1 \text { pass } t_{1}=63.85 \text { min } \\
\text { Total insert machining time for } i=7 \cdot t_{1}=446.95 \mathrm{~min}\end{array}$ \\
\hline Pass interval &
\end{tabular}

\begin{tabular}{|l|l|}
\multicolumn{1}{|c|}{ Table 5 Cooling data } \\
\hline \multicolumn{1}{|c|}{ Description } & \multicolumn{1}{|c|}{ Values } \\
\hline $\begin{array}{l}\text { Air pressure on input in } \\
\text { a vortex tube }\end{array}$ & 6 to 8 bars \\
\hline & \\
Measuring instrument & Rothewald Infra-Red digital thermometer with \\
& Laser Pointer \\
\hline $\begin{array}{l}\text { Temperature measuring } \\
\text { range }\end{array}$ & $-50{ }^{\circ} \mathrm{C}$ to $750{ }^{\circ} \mathrm{C}$ \\
\hline Measured temperature & $-11^{\circ} \mathrm{C}($ see Fig. 5) \\
\hline Measuring accuracy & about $\pm 2 \%$ \\
\hline
\end{tabular}

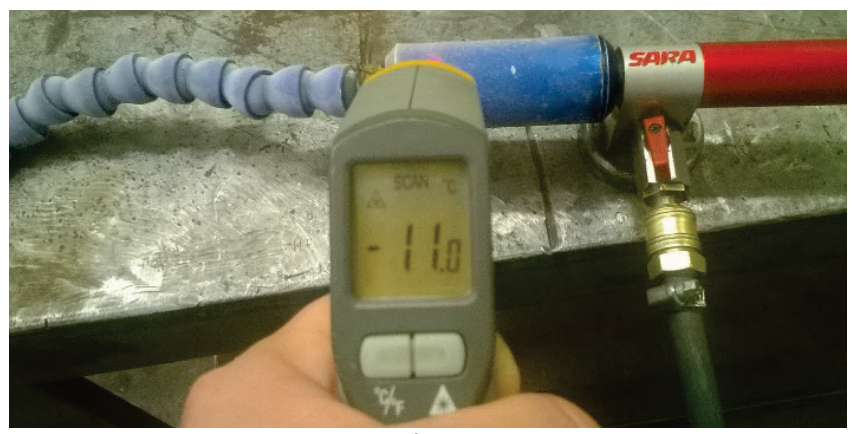

Figure 5 Temperature measurement of cold air on vortex tube outlet in workshop condition

Application of spot cooling of the tool with cold air during final machining of induction hardened raceway gave is shown in Figs. 6 and 7. 


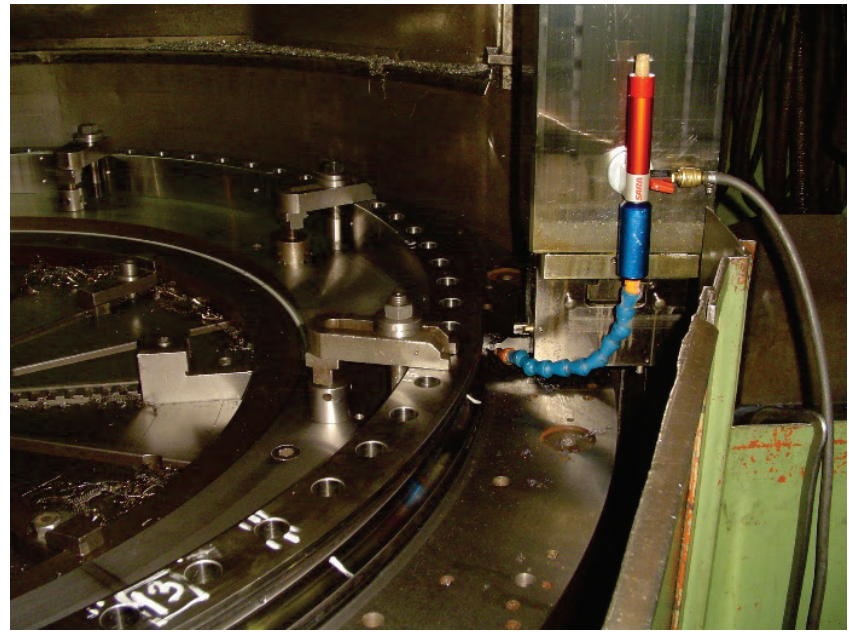

Figure 6 Final machining of induction hardened race with spot cooling

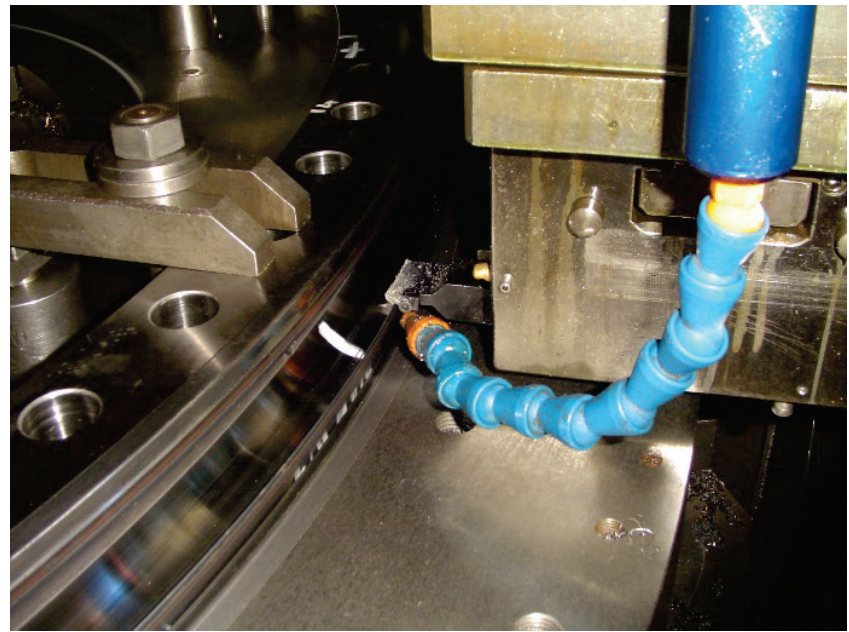

Figure 7 Detail of final machining with spot cooling

\section{DISCUSSION}

The following results have been obtained:

- First, it was noticed that there is no characteristic color of the machined chip.

- There is no characteristic point of burnout chips on cutting edge due to the fact that cold air decreases temperature in point of contact for cutting edge and raceway.

- During machining without cooling only one side of the insert was used for machining of one raceway (1 ring), and after the application of spot cooling, one side of the insert performed machining on two raceways (2 rings). That was a surprising result because the insert is expansive (135€/piece) and it has only two sides (round insert which could be set in two positions). The durability of the insert was increased for $100 \%$ during machining of induction hardened raceway with one pass time of about 1 hour.

- The number of workpieces was 27 inner and 27 outer rings. It means that with spot cooling one insert machined 4 rings instead of only two; therefore, to machine the rings 14 inserts were spent instead of 28 inserts without cooling. This allows for significant savings. That is important information for the machining plan because ordering 20 inserts (minimum) costs less related to orders of only one insert which could cost from $€ 160$ to $€ 215$.

- When machined with spot cooling, the quality of surface finish is improved due to minimized heat input (also, material accumulation on the insert tip is less).

- Finally, decreasing of raceway roundness after final machining from 0.2 to $0.1 \mathrm{~mm}$ and changes in measure over balls is less than $0.1 \mathrm{~mm}$, which means that there is no reason for additional machining of both rings before mounting.

The increase in operating costs due to cooling air consumption is not significant. For cost of $0.02 € / \mathrm{m}^{3}$ of the compressed air and consumption $0.27 \mathrm{~m}^{3} / \mathrm{h}$, the compressed air cost is $€ 0.4$ for an hour of the machine work.

\section{CONCLUSION}

Air spot cooling during turning of hard materials could extend tool life of CBN cutting inserts up to $100 \%$, which could lead to significant savings at tool purchasing. Heat input in the hardened area had been significantly decreased, which decreased dimensional change measured 24 hours after final machining of the raceway. The quality of surface finish was improved, too.

In accordance with obtained results, the vortex tube aircooling systems proved to be effective at dissipating the heat from the tool tip, proving that air-cooling is an effective method of cooling tool tip.

\section{REFERENCES}

[1] Dyck, M. (2007). Beitrag zur Analyse thermisch bedingter Werkstückdeformationen in Trockenbearbeitungsprozessen. Dr.-Ing. Dissertation wbk Institute of Production Science, Karlsruhe.

[2] Klocke, F., Kneer, R., Burghold, M., Deppermann, M., Peng, B., \& Puls, H. (2018). Modelling and Compensation of Thermoelastic Workpiece Deformation in Dry Cutting. In: Thermal effects in complex machining processes. Lecture Notes in Production Engineering. Springer, Cham, Switzerland, 63-94. https://doi.org/10.1007/978-3-319-57120-1

[3] Aydin, M., Karakuzu, C., Uçar, M., Cengiz, A., \& Çavuşlu, M. A. (2013). Prediction of surface roughness and cutting zone temperature in dry turning processes of AISI304 stainless steel using ANFIS with PSO learning. International Journal of Advanced Manufacturing Technology, 67(1-4), 957-967. https://doi.org/10.1007/s00170-012-4540-2

[4] Weinert, K., Inasaki, I., Sutherland, J. W., \& Wakabayashi, T. (2004). Dry machining and minimum quantity lubrication. CIRP Annals - Manufacturing Technology, 53(2), 511-537. https://doi.org/10.1016/S0007-8506(07)60027-4

[5] Sharma, V. S., Dogra, M., \& Suri, N. M. (2009). Cooling techniques for improved productivity in turning. International Journal of Machine Tools and Manufacture, 49(6), 435-453. https://doi.org/10.1016/j.jjmachtools.2008.12.010

[6] Nandy, A. K., Gowrishankar, M. C., \& Paul, S. (2009). Some studies on high-pressure cooling in turning of Ti-6Al-4V. International Journal of Machine Tools and Manufacture, 
49(2), 182-198. https://doi.org/10.1016/j.jimachtools.2008.08.008

[7] Duspara, M., Kosec, B., Stoić, M., Kramar, D., \& Stoić, A. (2013). Application of vortex tube for tool cooling. Journal of Production Engineering, 16(2), 41-44.

[8] Lahres, M., Doerfel, O., \& Neumüller, R. (1999). Applicability of different hard coatings in dry machining an austenitic steel. Surface and Coatings Technology, 120-121, 687-691. https://doi.org/10.1016/S0257-8972(99)00359-X

[9] Choi, H. Z., Lee, S. W., \& Jeong, H. D. (2002). The cooling effects of compressed cold air in cylindrical grinding with alumina and CBN wheels. Journal of Materials Processing Technology, 127(2), 155-158.

https://doi.org/10.1016/S0924-0136(02)00117-6

[10] Abdelghany, S. T. (2018). Three-Dimensional Computational Investigation of the Power Separation and Flow Anatomy in the Vortex Tube. Journal of Scientific and Engineering Research, 5(1), 197-212.

[11] Pinar, A. M., Uluer, O., \& Kirmaci, V. (2009). Optimization of counter flow Ranque-Hilsch vortex tube performance using Taguchi method. International Journal of Refrigeration, 12(6), 1487-1494. https://doi.org/10.1016/j.jrefrig.2009.02.018

[12] Liu, J. \& Kevin Chou, Y. (2007). On temperatures and tool wear in machining hypereutectic Al-Si alloys with vortex-tube cooling. International Journal of Machine Tools and Manufacture, 47(3-4), 635-645. https://doi.org/10.1016/j.jimachtools.2006.04.008

[13] Sutter, G. \& Ranc, N. (2007). Temperature fields in a chip during high-speed orthogonal cutting-An experimental investigation. International Journal of Machine Tools and Manufacture, 47(10), 1507-1517.

https://doi.org/10.1016/j.jmachtools.2006.11.012

\section{Authors' contacts:}

Mladen BOŠNJAKOVIĆ, PhD, Assis. Prof.

Corresponding author

Technical Department, College of Slavonski Brod,

M. Budaka 1, 35000 Slavonski Brod, Croatia,

mladen.bosnjakovic@vusb.hr

Olivera MAGLIĆ, MSC

Technical Department, College of Slavonski Brod, Dr. M. Budaka 1, 35000 Slavonski Brod, Croatia, omaglic@vusb.hr

Dragomir MOŠKUN, MSc

Đuro Đaković Strojna obrada d.o.o.

dr. Mile Budaka 1, 35000 Slavonski Brod, Croatia

dmoskun@strojna-obrada.hr

Zoran CRNAC, MSC

Technical school,

E. Kumičića 55, 35000 Slavonski Brod, Croatia

zcrnac2@gmail.com 